\title{
Understanding the Urban Sprawl in the Mid-Size Latin American Cities through the Urban Form: Analysis of the Concepción Metropolitan Area (Chile)
}

\author{
Carolina Rojas ${ }^{1}$, Iván Muñiz ${ }^{2}$, Joan Pino ${ }^{3}$ \\ ${ }^{1}$ Department of Geography, Faculty of Architecture, Urbanism and Geography, University of Concepción, \\ Center for Sustanaible Urban Development - Chile, Concepción, Chile \\ ${ }^{2}$ Department of Applied Economics, Autonomous University of Barcelona, Barcelona, Spain \\ ${ }^{3}$ CREAF (Center for Ecological Research and Forestry Applications), Autonomous University of Barcelona, \\ Barcelona, Spain \\ Email: crojasq@udec.cl
}

Received March 9, 2013; revised April 12, 2013; accepted May 12, 2013

Copyright (C) 2013 Carolina Rojas et al. This is an open access article distributed under the Creative Commons Attribution License, which permits unrestricted use, distribution, and reproduction in any medium, provided the original work is properly cited.

\begin{abstract}
Latin American cities, like those from North America and Europe, experience problems of urban sprawl. However, few studies have dedicated exclusively to this phenomenon in specific cities, and this omission is particularly noticeable regarding cities not considered among the megalopolis of the continent. The present work analyzes urban sprawl through an urban form in the Concepción Metropolitan Area, Chile, between 1990 and 2009, considering local aspects that may have played a role in the process. The main empirical results obtained from this study reveal a metropolitan area that has expanded intensely over a 20 -year period, growing from 9000 hectares to more than 17,000 ha for a $96 \%$ increment in the built-up area. The new urban surfaces consolidate a central conurbation that strengthens the role of the main downtowns, with less-intense occupation towards the sub-centers but in a structure that follows the transportation infrastructure. Over the last 20 years, the distance between the shapes has grown progressively by around $2 \mathrm{~km}$, increasing the size of the ellipse by more than $1000 \mathrm{~km}^{2}$. In particular the complexity of the urbanized surfaces has grown, becoming more irregular in shape and less compact as they come to occupy larger areas. So our principal findings include: an increment of nearly $100 \%$ in the urban surface, the importance of a polycentric urban structure in the process of consolidation as a support for analyzing different spatial dynamics, and the growing morphological irregularity of the territory of the sprawl.
\end{abstract}

Keywords: Urban Sprawl; Latin American Cities; Metropolitan Areas; Geographical Information System

\section{Introduction}

In Europe and especially the United States, urban sprawl has been the subject of a consolidated line of research since the 1960s. However, in Latin America, this phenomenon only very recently has become a point of interest for the academic community.

In general, Latin American literature has focused on contextualizing the phenomenon of sprawl within a broader framework, taking urban sprawl, polycentrism, functional specialization, network economies, and the growing privatization of the urban space to be reflections of a new type of globalized city that grows and changes according to the logic of the market and improvements in the fields of transport and telecommunications. This contextualization has allowed elaborating a coherent tale regarding the changes that have taken place. However, there is a clear lack of symmetry in terms of the quality and sophistication of the theoretical tale and the scant empirical evidence on which it is based.

Urban sprawl increases the cost of supplying public services; occupies spaces with elevated agricultural, ecological, or landscape value; and leads to a model of mobility based on the automobile, which is expensive, unequal in the distribution of opportunities, and environmentally unsustainable [1-3]. Furthermore, urban sprawl often accompanies or accentuates characteristic problems of Latin American cities such as phenomena of social segregation, difficult access to employment for the most disadvantaged groups, or the geological vulnerability of some urbanized zones [4-6]. Bearing in mind the 
economic, social, and environmental importance of urban sprawl, a better understanding of this phenomenon is indispensable.

This work is intended to characterize the phenomenon of urban sprawl that has occurred in Concepción during the last 20 years. In order to achieve this, the rhythm of land consumption and its relation to the existing spatial structure-Concepción is a Medium size Chilean city, polycentric and with an interesting particularity, it counts on two CBDs, almost twins and very close each other. Then, two indices of urban form are now calculated [7], in order to calculate the evolution of the urban form adopted by the dimension of the sprawl [8]. As indicated in the specialized literature. A drop of the compactness index and an increase in the complexity index imply a greater sprawl. The information obtained will allow to determinate the rhythm of land consumption, its preferential location, proximity among urban zones and irregularity (Complexity index).

The rest of this article is organized as follows: Section two is dedicated to the recent transformations of Latin American cities and various visions of urban sprawl. Section three deals with the concept of urban sprawl, and section four presents the methodological aspects related to processing satellite images, extracting urbanized surfaces, and calculating the metrics of the forms and ellipse associated with the measurement of sprawl in terms of the distance between the shapes of the expansion. In section five, the case study is characterized, and the results are presented according to the proposed objectives, detailing the urban growth according to the structure of the downtowns that make up the Concepción metropolitan area (CMA), the new spatial shapes, and the sprawl of the urbanized surfaces. Finally, section six contains the main conclusions of the study.

\section{Recent Transformations in Latin American Cities}

Many cities are currently growing faster than what their planning can accommodate, and urban growth is becoming a worrisome global reality that increasingly affects the balance between humans and ecosystems. In this sense, cities are good examples of complex systems that require enormous effort to maintain their equilibrium [9]. Understanding urban growth is a fundamental planning concern. Environmental and social challenges require transforming rapid urban growth into sustainable growth, with an internal balance between economic activity, population growth, infrastructure, pollution, waste, and noise [10].

Urban growth is a worrisome reality that affects global urban ecosystems and is even considered to be a type of global environmental change [11]. Such growth is seen as a potential threat to ensuring adequate housing, sanitation, health, and transportation services in a sustainable urban environment, especially in the cities of less developed countries like those in Latin America.

As a whole, Latin America, including Mexico, constitutes one of the most urbanized regions of the world, with an urban population that grew rapidly from 69 million in 1950 to 448 million in 2007. By 2025, 575 million people are expected to be living in Latin American cities. This notable increment (78\%) is higher than that one for Europe, Africa, and Asia for the same dates [12]. The intensity, speed, and impact on natural systems of this accelerated urban growth in Latin American cities, especially considering the ever-more-segregated distribution of the population groups, has awoken interest in the matter.

The rapid urbanization in Latin America has been largely explained by its industrial development between the 1950s and 1980s, and the changing role of private capital in territorial organization beyond its competencies in the economic model. In this sense, all Latin American countries are experiencing transformations due to globalization as well as endogenous factors. Although their origins are debatable, these factors are related to urban effects such as new modalities of metropolitan expansion, suburbanization, polycentralization, social polarization, residential segregation, and the fragmentation of the urban structure [13]. Three types of regions can be distinguished within the context of this new, quickly growing urban configuration: first are countries with more than $80 \%$ of the population living in urban areas (Argentina, Chile, Uruguay, Venezuela); second are countries with $50 \%$ to $80 \%$ of the population in urban centers (Mexico, Brazil, Ecuador, Colombia, Cuba, Bolivia, Peru); and third are countries with less than $50 \%$ of the population in cities (Paraguay) [14]. In terms of urban development, Mexico City, Sao Paulo, Rio de Janeiro, and Buenos Aires are world-class examples of large cities with extensive growth of the urbanized surface, whereas Santiago de Chile stands out as a metropolitan area whose growth is primarily based on the creation of new downtowns and the use of agricultural land.

The large metropolitan areas of Latin America are complex, competitive, and dynamic hubs in which these tendencies are notorious. Although most cities in Chile are mid-sized, they, too, reveal certain restructuration processes that should be mentioned. Chile is highly urbanized, with more than $80 \%(13,090,113$ inhabitants $)$ of its population living in urban areas of over 5000 inhabitants. However, this country is characterized by mostly mid- to small-sized cities. Three metropolitan areas (Santiago, Concepción, Valparaíso), all located in the macrocentral zone, reflect spatially concentrated development, with more than 6 million inhabitants, which represents 
$48.3 \%$ of the population. Chile is centralized in the sense that more than 5 million individuals live in the city of Santiago alone.

The changes experienced by Chilean cities, like those of the rest of Latin America, are described as being tied to globalization, particularly since Chile began to apply the neoliberal model as early as the 1970s. One primary transformation is the shift from relatively compact structures associated with the foundational model to diffuse models present in peripheral areas or the places towards which the growth of these cities tends [15].

\section{Urban Sprawl in Latin America}

The repercussions of the urban changes resulting from the effects of globalization and the neoliberal model can be seen in new expressions and spatial forms of growth that have led mainly to an unequal distribution of the population based on the social condition and ever more disperse urban structures. The most important phenomenon is known as "peripheralization". This is an "oil stain" type of growth process at the edges of the city, with peripheral settlements typically being located in areas where the land value and residential quality are low [14]. Peripheralization has favored the development of disperse sprawl, fragmented spaces, polycentralities, residential segregation, and landscapes dominated by large commercial centers and highways. As noted by [16], it seems incredible how, over the course of a few decades of urbanization, the neoliberal model has acted as one more agent in the territorial ordering, redefining the relation between the public and the private, with a clear preference for the latter.

No single tale explains the causes of urban sprawl. Rather, at least three approaches have been taken into account to this end, and the theoretical roots of these can be clearly differentiated. First, according to the natural growth approach, urban sprawl is the logical result of an increase in the per capita income, declining transportation costs, and innovations in the field of telecommunications [17]. Greater per capita incomes lead to higher demands for single-family housing; lower transportation costs allow financing housing farther from the workplace; and innovations in telecommunications (e.g., telecommuting) make physical proximity increasingly less important. Second, the economic restructuration approach emphasizes the spatial repercussions of a new economic logic marked by the globalization of capitalism. From this perspective, the emergence of new sub-centers, the appearance of commercial centers or business parks on the periphery, and the phenomenon of sprawl are the main features of a new urban model stemming from globalization in a context in which the private sector tends to impose itself over the public sector. Finally, the path-dependency approach breaks with the economictechnological determinism of the two previous approaches, indicating that forces that are global in nature feed sprawl, but that these forces interact with the local context, where history, geography, and urban planning are important. In this sense, sprawl is understood to be a problem of poor territorial planning due to poor housing policies $[18,19]$.

In general, the study of the causes of urban sprawl in the USA has followed the first approach (natural growth), with special emphasis on the role of technological change. In Latin America and the United Kingdom, the second approach (economic restructuration) has been more popular, associating urban sprawl with the growing liberalization of the economy that has occurred in Latin America since the 1980s. Finally, in continental Europe, the third approach (path-dependency) is the most common since not all European countries and cities experience processes of sprawl. The countries that have experienced the most intense sprawl are precisely those in which the public sector has had a waning presence in the housing policy and urbanism.

In Latin America, the study of urban sprawl is first characterized by the fact that this topic is not generally the subject of specific analysis. Research on sprawl tends to form part of broader studies of the spatial transformations of the city that includes aspects such as the decentralization of the population and activity, the formation of sub-centers, the emergence of a new geography of consumption and leisure, spatial segregation or the constitution of networks, and new patterns of mobility. Although all these phenomena are related to a certain degree, specific studies should be proposed to delve further into each one of them. Secondly, the economic and social costs of sprawl are those that have been granted the most attention. Therefore, studies that tackle the environmental aspects of sprawl, especially in relation to the occupation of areas with elevated ecological and/or landscape value, are lacking. In the third place, most studies have examined the causes of sprawl through the lens of economic restructuration. The problem with this approach is that it lacks a certain economic determinism in the same way that the natural growth approach lacks a certain technological determinism. The path-dependency approach allows a more detailed look at the economic-social circumstances-from land and housing policies to the power of local agents in planning or the policy of inflation - that have interacted with the global tendencies feeding the process of sprawl.

One of the main reasons by which sprawl in Latin American cities has not been considered an issue of preferred analysis is that it has been refused until recently. In general, other labels were preferred rather than alternatives to "dispersion". The fundamental reason behind 
this refusal is that in both USA and Europe is only given within a context of population stagnation. This implies the reorganization of the residential and productive space whose net balance implies a higher consumption of land. If on the contrary a population growing is given as well as the land consumption, the term "urban growing" becomes more usual and if what id given is the functional annexation of peripheral area, the term "metropolization" should be used. These are two processes that certainly have determined the evolution of Latin American cities. However, it must be recognized that the forms adopted by some Latin American metropolis are very similar to United States cities qualified as dispersed. On the other hand it also must be taken into account that in some Latin American countries the rural-urban migratory processes have been stopped and the population growing of some metropolis has been clearly below the land consumption rates. For all this, it seems appropriate to start analyzing the evolution of the shape of the Latin American cities under the perspective of dispersion.

Empirical works that have addressed dispersion of Latin American cities by mean of indices of urban form are scarce. Among them, the index by Huang et al. (2007) is noteworthy [20]. This index allows testing for the presence of spatial urban dispersion patterns only in major Latin American cities such as Buenos Aires, Córdoba, Porto Alegre, Rio de Janeiro, Sao Paulo, Santiago, San Salvador, Tegucigalpa, Guadalajara, Ciudad de México, Monterrey, Managua, Montevideo, Bogotá, Caracas, Quito and Guatemala. Even without considering measurement in metropolitan areas of medium size, urbanization trends reflect the maintenance of more compact and dense shapes, mainly in cities that have manifested a radial growing influenced by a more European foundational planning, in contrast to the general trend that indicated a greater similarity towards the patterns of the US cities [20].

In the case of Chilean cities, urban expansion has been characterized by the dominance of the private automobile, the emergence of new downtowns and the installation of commercial shopping centers. This type of urban sprawl has been specifically characterized by low-density peripheral expansion; new centralities; new more fragmented, heterogeneous spaces; and residential segregation [15]. When a closer look is given at these transformations, the case of Santiago de Chile immediately stands out. This city of more than 5 million inhabitants is closely tied to the American process, experiencing accelerated sprawl and being cataloged as a suburbanized, extremely segregated, fragmented, polycentric region with imprecise limits whose expansive dynamics have incorporated nearby urban and rural lands, configuring a vast periurban area [21]. Surprisingly, not only are these processes notorious in the capital, but they are also present in the rest of the metropolitan areas (Concepción, Valparaíso) and regional capitals with more than 100,000 inhabitants (known as "regional cities") in varying phases of the metropolitan life cycle [15].

\section{Methodology}

By means of a GIS-based approach to urban form, we first selected the major built-up polygons of urban growth in the CMA from Landsat images and then calculated a set of spatial indices concerning the size and shape of these built-up areas. In order to understand the spatial pattern of urban sprawl and the alterations in urban form over time, the changes in these indices from 1990 to 2009 were tracked in terms of the size and spatial position of the corresponding urban areas using linear models.

The proposal of this methodology is to apply a set of spatial indices in order to understand the evolution of urban form of CMA, even though it is not designed to this study area, they are perfectly applicable to other metropolitan areas of Latin America. The measures could be useful to understand the link between land use pattern and urban sprawl.

\subsection{Image Classification and Selection of Built-Up Areas}

The remote sensing techniques used here constitute powerful tools for studying urban growth and sprawl because they facilitate the identification of different land uses and covers. These techniques can be applied to satellite images to identify built-up areas. The main methods used to identify urban and built up areas are supervised classifycation $[20,22,23]$ and principal component analysis $[24$, 25]. In this study, we applied supervised classification using maximum likelihood with over $70 \%$ accuracy.

We used six Landsat orthorectified images that completely covered the CMA: two images from 1990 (path 001/row 085: 22 January 1990; path 001/row 086: 22 January 1990), two from 2000-2001 (path 001/row 085: 18 January 2000; path 001/row 086: 22 December 2001), and two from 2009 (path 001/row 085: 18 January 2009; path 001/row 086: 18 January 2009). The 1990 and 2009 images were obtained with the Thematic Mapper (TM) sensor at a spatial resolution of $30 \mathrm{~m}$, and the 2000 and 2001 images with the Enhanced Thematic Mapper (ETM + ) sensor at a resolution of $30 \mathrm{~m}$. The images from path 001/row 085 and path 001/row 086 were joined, generating three mosaics: one for 1990 , one for 2000 , and one for 2009. The spatial reference system in the study was UTM (WGS84, zone 18S).

The built-up area was identified with supervised classification and principal component analysis. The first component retained more information about the built-up 
area, the second about vegetation, and the third about water. Subsequently, using these three bands, a supervised maximum likelihood classification was performed and the images were reclassified into either urban (builtup) or non-urban areas (two classes).

\subsection{Landscape Metrics of Built-Up Areas}

There are numerous studies that have analyzed urban dispersion through the calculation of urban form indices, making an intense GIS use. The three more utilized indices are: compactness index, complexity index and to a lesser extent, the porosity index [20,23,26-29].

In this study, we calculated two indicators using spatial metrics based on the area $(A)$ and perimeter $(P)$ of the built-up areas in 1990, 2000, and 2009. These indicators are:

Compactness of the largest path index (CLPI): This index measures landscape fragmentation (Equation (1)). When the shape is more regular and the patch number is smaller, the index value is larger [20] (Equation (1)):

$$
\text { CLPI }=\frac{2 \pi \sqrt{A / \pi}}{P}
$$

Complexity index (CO): This index measures the irregularity of shapes. It is a medium weighting of the fractal dimension index (Equation (2)). The higher values indicate greater complexity. The fractal dimension is discussed in [7].

$$
\mathrm{CO}=\frac{\sum_{i=1}^{i=n} \frac{2 \ln 0,25 P i}{\ln A i}}{N} * \frac{A i}{\sum_{i=1}^{i=N} A i}
$$

Compactness of forms is considered an antonym of the sprawl [29] and therefore, an urban expansion associated to more compact zones. Furthermore, it relates areas of greater population density closer to the services centers and jobs, promoting a lesser land consumption. It also has been related to less fragmented forms, by considering the number of forms of a greater urban zone [29]. Complexity indicator associated to a more disperse growing is related to a more irregular edge expansion and therefore, to more complex spaces in its integration and urban connection.

\subsection{Directional Distribution (Standard Deviational Ellipse)}

This technique comes from the ecological study of the extension of animal habitats and consists basically of obtaining a bivariate confidence interval corresponding to the coordinates $\mathrm{X}$ and $\mathrm{Y}$. These define the major and minor axes of an ellipse with the smallest possible area. Then the standard distance (Euclidian) is calculated be- tween the locations $\mathrm{X}$ and $\mathrm{Y}$ of growing zones. In this study, the ellipse is used as a measure of the sprawl from the urban areas or built-up areas.

The size of the confidence ellipse depends on the number of standard deviations of the distance of the urban areas with respect to downtown metropolitan Concepción. In this case, we use two deviations, covering $95 \%$ of the urban forms.

The interpretation is interesting to analyze because of that area resulting as an indicator of sprawl related with the distance to central business center, and if the evolution to urban growth tends to extended, it increases the territory could be interpreted as a spatial process of urban sprawl or first steps of this phenomenon. Therefore from the points in space and the angle of the main axis of the ellipse, as an indicator of the geographic orientation of the urban growth and interpret in which areas with another pattern it is experimenting or starting a process of urban sprawl.

The increment of the distances of the new urban forms along to the loss of proximity to the center reflects a more deficient model for connecting urban forms and the dependence of the existence of highway of transportation networks. Finally, related to a technical point, the tool Directional Distribution of ArcGIS (Standard Deviational Ellipse) is used.

\section{Study Area}

The CMA is located in central-southern Chile $\left(36^{\circ} 35^{\prime} \mathrm{S}\right.$ $37^{\circ} 00^{\prime} \mathrm{S}$ and $\left.72^{\circ} 45^{\prime} \mathrm{W}-73^{\circ} 15^{\prime} \mathrm{W}\right)$. This is a coastal territory or the internal margin of a trench with tectonic origins that contains modeled plains and terraces of fluvial origins [30]. According to the delimitation proposed by the Concepción Metropolitan Regulatory Urban Plan (2003), the city is defined as a functional, hierarchical territory made up of 11 apparently closely related townships (municipalities): Chiguayante, Concepción, Coronel, Hualqui, Hualpen, Lota, Penco, San Pedro de la Paz, Santa Juana, Talcahuano, and Tomé. These municipalities congregate a population of over 900,000 inhabitants and a density of 318.9 inhabitants per $\mathrm{km}^{2}$ [31]. This metropolitan area stretches along $60 \mathrm{~km}$ of coastline from the township of Tomé (the northern limit) to that of Lota (the southern limit), including the entirety of the townships: Chiguayante, Concepción, Coronel, Hualqui, Lota, Penco, San Pedro de la Paz, Santa Juana, Talcahuano, and Tomé.

The CMA covers a surface of $2830.40 \mathrm{~km}^{2}$, or $7.63 \%$ of the regional surface, and its population constitutes $48.49 \%$ of the total population and $57.31 \%$ of the urban population of the Biobío Region. The inhabitants reside mainly in urban zones with low slopes (97\%) located on the coastal plain. These intermediate cities are located on 
the shores of the Biobío River and coexist with complex, conditioning geographic elements (beaches, dunes, rocky cliffs, marsh areas, river mouths, wetlands, bays, peninsulas, islands, gulfs, and the coastal mountain range). Given its complex geography and climate, this territory is heavily exposed to recurring natural phenomena (floods) and, environmentally, is very vulnerable to urbanization.

The urban structure (Figure 1) is heavily influenced by the downtowns of Concepción and Talcahuano, the urban articulators of this eminently industrial space that has experienced heavy urban growth. It is important to note that this is the second urban concentration in Chile, with a traditional presence of industrial and service activities. Recent socio-spatial studies carried out regarding this territory have revealed certain dynamics that are related to the aforementioned rapid urban growth of the last decade (2000-2010). The CMA constitutes a unit of greater scale and size, characterized by the existence of flows of goods, services, and persons; productive and economic specialization; and an increasingly hierarchical economic and urban organization of the cities [32]. In 1975, the urbanized surface was 5219.6 ha, concentrated in downtown Concepción and Talcahuano; in 1990, this area grew up to 9012.2 ha, conforming the central conurbation around the transport routes that unite these two downtowns; and in 2001, the urbanized surface reached 12,000 ha, experiencing an increase of 33\% [33].

Although earlier information justified the population growth and, therefore, that of the urbanized surface in terms of migration [34], at present, this situation is more complex and also has to do with other spatial factors that may be natural or biophysical in nature (altitude, slope, distance to forests, natural spaces and water bodies) as well as anthropogenic factors such as the tendency for new growth to be concentrated in areas that may be near socioeconomic points of interest (downtown, universities, shopping centers, etc.) and highway networks. These areas are environmentally vulnerable given the geographic restrictions of the emplacement of the most urbanized zone of the CMA [35].

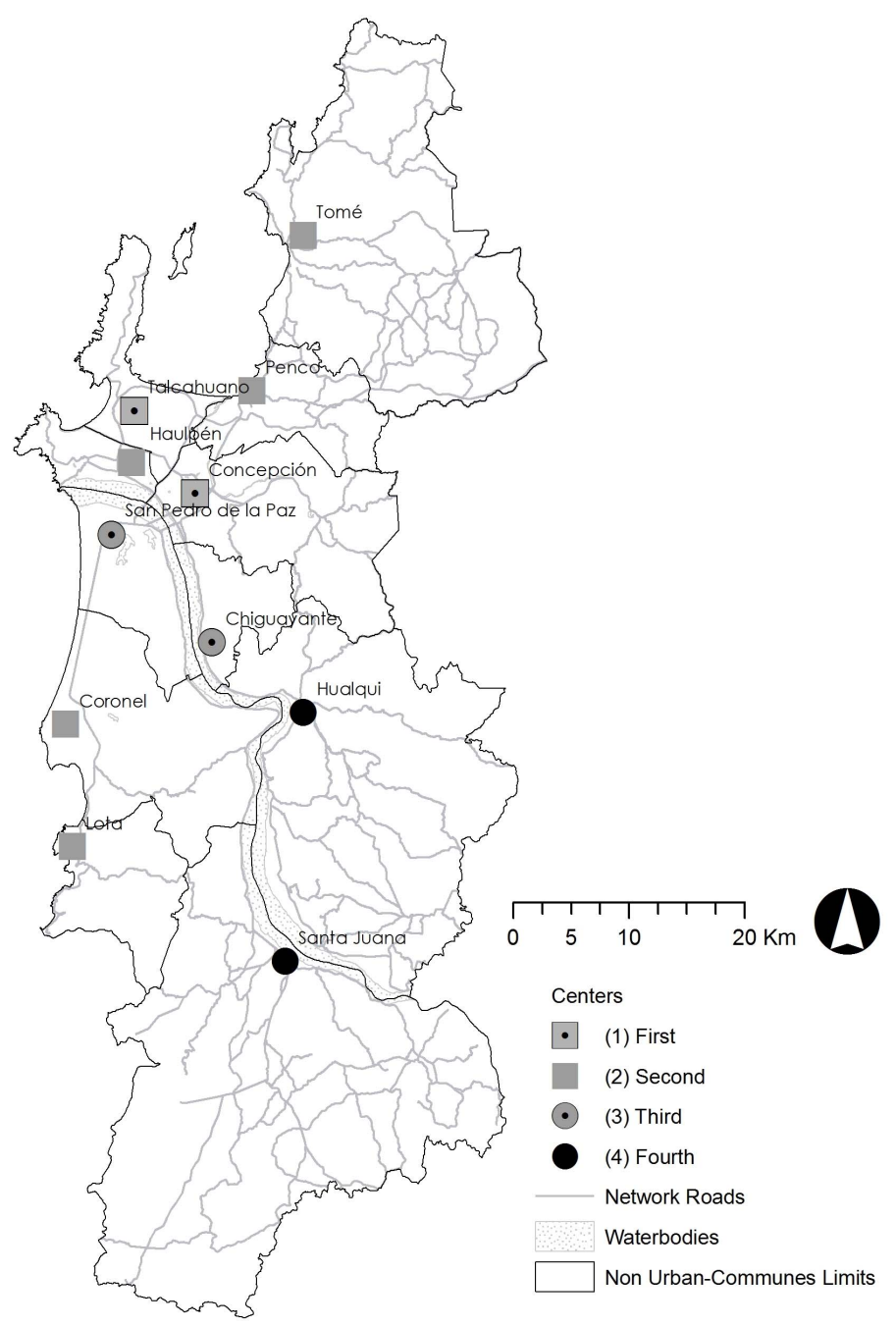

Figure 1. Metropolitan centers in CMA. 
The organization of recent urban growth attempted to increase the density of certain central spaces of renewal. However, this growth has spilled over into the periphery under a model of low densities, decreasing the compactness of the city. Functionally, the settlements are organized in a restricted polycentric model, with Concepción and Talcahuano acting as main downtowns and the remaining townships acting more as sub-centers with a much lower spatial influence than the two main downtown areas; these sub-centers are also more localized in terms of their surroundings [32]. The morphology of the sub-centers is completely dominated by a central conurbation; that is, an oil stain phenomenon that spreads over the peripheral limits of the historically consolidated spaces. Some of the main factors that have favored this representation include the distance to the urban downtown (taken to be the civic downtown of the city of Concepción) and the distance to highways and the transport infrastructure. These factors directly affect the formation of a tentacular growth structure. Finally, the recent urban growth structures have led to some complex and conflictive consequences. One such outcome is socio-spatial segregation related to the location of social housing, its concentration, and the value of the land on which it is built [36]. Another consequence is the impact on swamplands: over the last three decades, 23\% (1.734 ha) of the area occupied by swamplands has been lost due to the expansion of the city, leading to swamplands with different degrees of habitat fragmentation, loss, and alteration [37].

\section{Results}

\subsection{Urban Growth and Urban Spatial Structure}

Built-up areas in the CMA grew from 9021 ha in 1990 to 12,007 ha in 2000 and 17,683 ha in 2009 (Table 1 and Figure 2). Built-up areas increased by $28 \%$ and $47 \%$ in the first (1990-2000) and second (2000-2009) time periods; that is an annual rate of urban growth of about 639 ha for the overall time period. The population, however, grew $12 \%$ and $7 \%$ for the first and second periods, respectively (Table 1). Comparison of growth rates of population and land, much favorable for the second one, strongly validates the convenience of studying the spatial evolution of Concepción under the perspective of the urban sprawl.

The built-up areas increased differently at different places within the CMA. According to the hierarchy of the centers proposed by Rojas, Muñiz and García (2009), the first-order downtowns or central places (Concepción and Talcahuano, including Hualpén) consolidated and concentrated the central urban area of the CMA [32]. Concepción and Talcahuano are clearly the largest

Table 1. Built-up areas and population (1990-2000-2009).

\begin{tabular}{cccc}
\hline Years & $\begin{array}{c}\text { Built-up areas } \\
\text { (ha) }\end{array}$ & $\begin{array}{c}\text { Built-up areas } \\
\left(\mathrm{Km}^{2}\right)\end{array}$ & Population \\
\hline 1990 & 9392 & 9392 & 821,694 \\
2000 & 12,047 & 1204 & 922,651 \\
2009 & 17,683 & 1768 & 994,781 \\
\hline
\end{tabular}

Source Population: National Statistics Institute (2009) www.ine.cl.
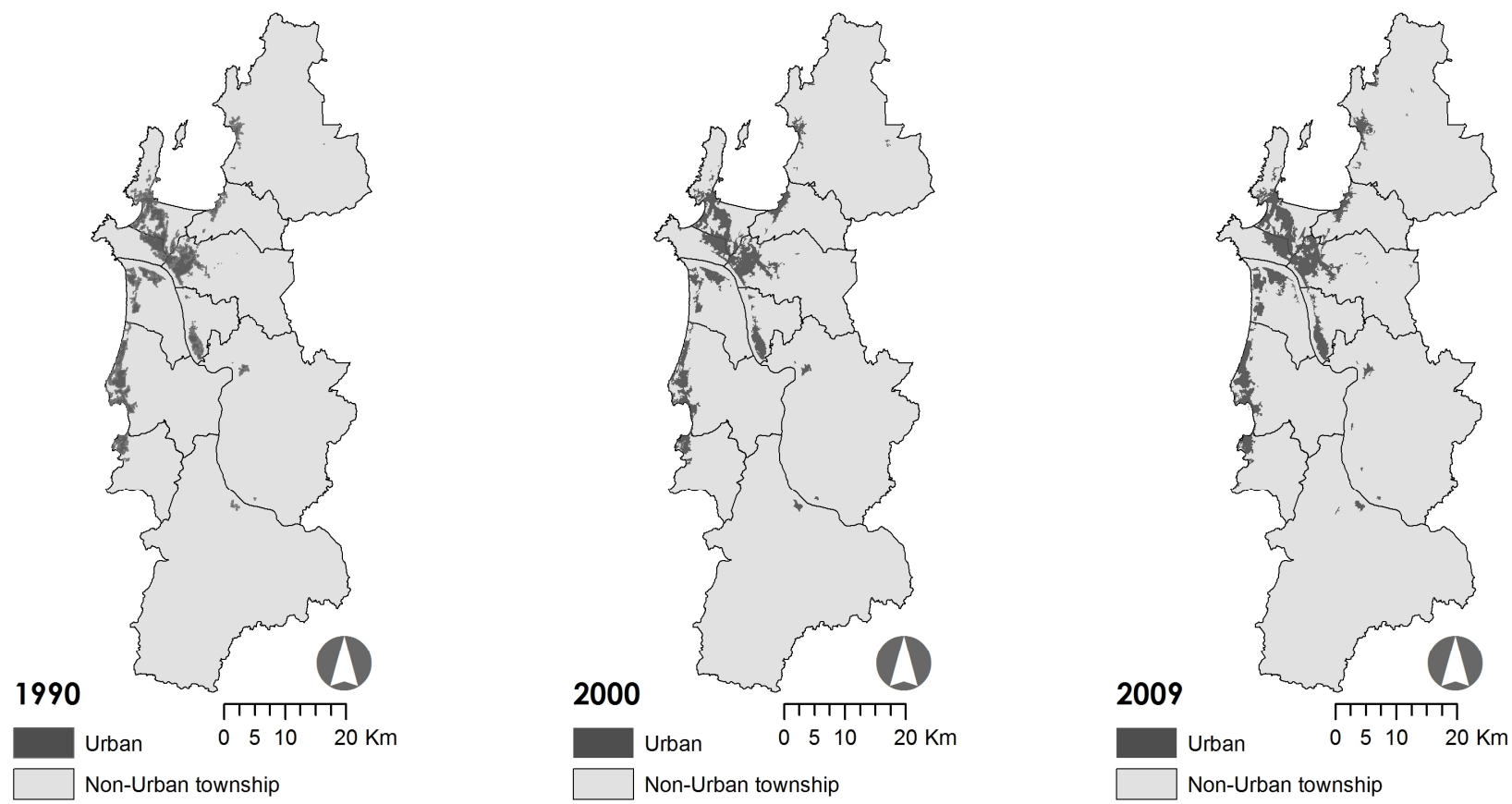

Figure 2. Urban area is equal to built-up areas in the CMA in 1990, 2000, and 2009. 
townships, with more than 3000 ha. In 2009, a trend to consolidate was observed in the urban centers of Concepción and Talcahuano, with an increment of built-up areas exceeding 3000 ha.

Third order or bedroom cities (Chiguayante and San Pedro de la Paz) have been added to the central conurbation following an oil stain model. The growth of the emerging center of San Pedro has been impressively fast, and the built-up area now exceeds 2000 ha. This central conurbation concentrated $71 \%$ of the total built area in the CMA in $1990,74 \%$ in 2000 , and $71 \%$ in 2009 . Thus, the tendency over time is for the central conurbation to maintain about $70 \%$ of the CMA population. However, new urbanizations began to emerge in the townships of Chiguayante, Hualpén, and San Pedro de la Paz since 2000. As a result, each of these townships now accounts for nearly 1000 ha of built-up areas.

In second-order downtowns or integrated cities (Penco, Tomé, Lota, and Coronel), urban occupation has been particularly intense around the transportation network, particularly in Penco and Tomé along the northern coast of the region, with more than 500 ha, below the 1000 ha. Growth in Coronel has been greater than 500 ha, but Lota has shown negligible growth. Growth was also minimal in fourth-order or rural downtowns with large rural areas (Hualqui and Santa Juana), and these built-up areas remained below 200 ha (Figure 3).

\subsection{Shape Patterns of Urban Sprawl}

Changes in these landscape metrics over time reveal a drop in compactness (from 0.65 to 0.56 ) in the first study period and an increment (from 0.56 to 0.59 ) in the second period. Conversely, complexity increased (0.009 to 0.016) in the first period and decreased in the second period, although values in 2009 were still higher than those in 1990 (0.016 to 0.012) (Table 2).

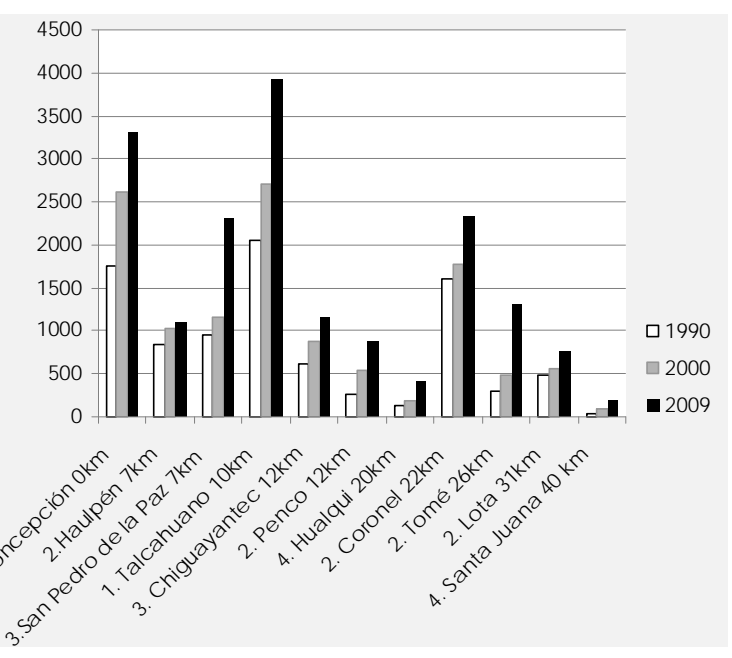

Figure 3. Increase of built-up area (ha) by township.
Table 2. Descriptive statistics of shape index $(\mathrm{N}=$ number of patches).

\begin{tabular}{ccccccc}
\hline Indices & 1990 & & 2000 & & 2009 & \\
& $(\mathrm{~N}=118)$ & & $(\mathrm{N}=66)$ & & $(\mathrm{N}=96)$ & \\
\hline & Mean & S.D. & Mean & S.D. & Mean & S.D. \\
$\begin{array}{c}\text { Compactness } \\
\text { (CLPI) }\end{array}$ & 0.65 & 0.17 & 0.56 & 0.17 & 0.59 & 0.15 \\
$\begin{array}{c}\text { Complexity } \\
\text { (COI) }\end{array}$ & 0.009 & 0.0003 & 0.016 & 0.0007 & 0.012 & 0.004 \\
\hline
\end{tabular}

The results regarding the central conurbation (Table 2) are also interesting. In 1990, the CLPI was 0.23 and the COI 0.009; in 2000, the CLPI was 0.16 and the COI 0.01; and finally in 2009, the CLPI was 0.17 and the COI 0.01 . These values indicate that the evolution of urban form is more clear in the most urbanized area (central conurbation) and that sprawl tends to less regular in compactness and more irregular in complexity.

The shape of the built-up polygons became less compact from 2000 to 2009 and at the same time that the complexity of these tended to increase (Table 2). Although our data do not permit a deeper analysis, the non-parametric Kruskall-Wallis test confirmed these trends in compactness and complexity at $\mathrm{p}<0.05$.

In general, non-significant or weak linear associations were found between the selected landscape metrics and the area and distance to the CMA centroid. The only significant relation took place between compactness and area, although the association was weak. The relation between these variables was negative; i.e., compactness decreased when the size of the built-up area increased (Figure 4).

\subsection{Urban Sprawl in the Concepción Metropolitan Area}

The possible causes of urban sprawl began to appear in the second half of the twentieth century and are related to industrialization and the migratory processes favored by the road for the development of scattered cores at flat and coastal sites. Due to the limitations imposed by the relief, the plains offered the best location, despite environmental restrictions, especially in the Concepción-Talcahuano conurbation. Given the development of the transport infrastructure, this conurbation also took on a star and tentacular shape.

The low-density model, another factor causing sprawl, has been present since the 1960s, that is, at the demographic and industrial peak, but paradoxically with scant investment in roadway infrastructure, which is absolutely necessary for industrial expansion. Although the urban planning of those years intended for the development to be concentrated and decentralized, the plans were not 

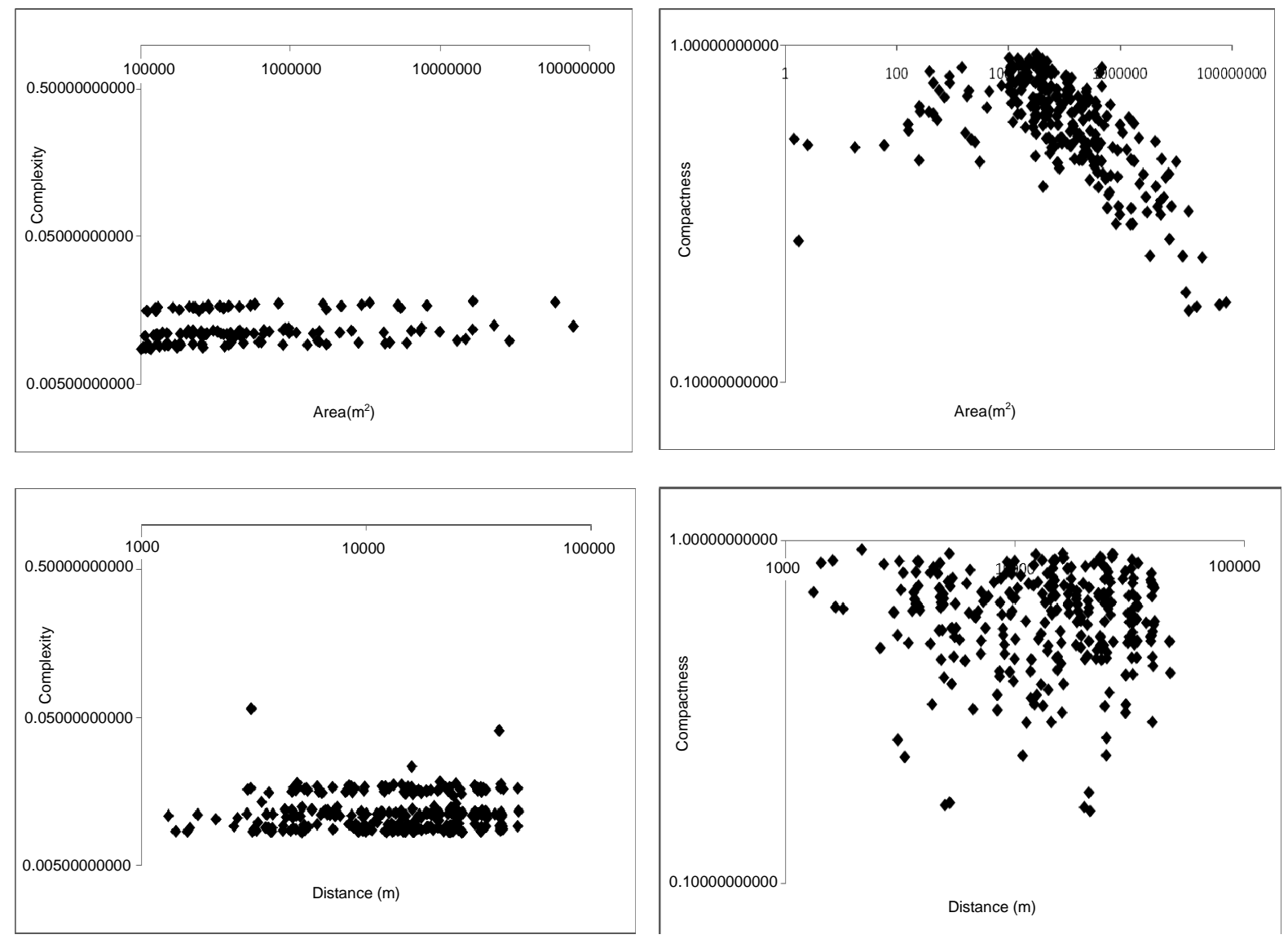

Figure 4. Scatterplot comparing compactness and complexity of built-up areas with respect to their area and distance from Concepción.

able to resolve the poorly distributed concentrations of the economically active population [38].

Urban planning and the current standards were another factor forcing sprawl in the 1970s (National Urban Development Policy). Both strengthened urban expansion, increasing the urban limit. However, a natural growth model, regulated by real estate speculation and industrial expansion, was adopted. In the 1980s, the market influence was maintained with overtones of urban renewal and infrastructure.

Results indicate that even the internal growing processes of the CMA demonstrate that the capacity is reducing as the complexity increases; it is still far from reaching the spatial patterns of major cities [20]. When compared to the Santiago metropolitan area, CMA is more compact and less complex than the Chilean capital city, which presents a CLPI of 0.038 and a CO of 1.44 [20].

The results indicate that in 1990, the area of the ellipse was $2657 \mathrm{~km}^{2}(265,723 \mathrm{ha})$, increasing to $3379 \mathrm{~km}^{2}$ $\left(337,915 \mathrm{ha}\right.$ ) in 2000 (an increment of $722 \mathrm{~km}^{2}$ ) and to $4330 \mathrm{~km}^{2}$ (433,019 ha) in 2009 (an increment of $951 \mathrm{~km}^{2}$ or $28 \%$ ). This indicates that the distance between the urban surfaces grew considerably, broadening the size of the ellipse. This evidence of the quantitative a result is related to the consolidation of the causes of sprawl in the 1990 s, especially in the cities of the conurbation that are classified as spatially dispersed and disarticulated [39].

The angles of orientation indicate the distribution and direction of the urban growth. In this sense, the orientation in $1990\left(8.9^{\circ}\right)$ was more centralized, with a more concentrated extension in the conurbation (TalcahuanoConcepción). However, in 2000, urban growth was directed towards San Pedro and Chiguayante, moving westward at $13.7^{\circ}$, a tendency that was maintained in 2009 , with an angle of $14.8^{\circ}$. According to the results and the factors forcing sprawl in the CMA, the urban expansion that began to increase in the 1990s found an ideal scenario for intensely disperse and agglomerated growth on the coastal plain (Figure 5).

\section{Conclusions}

The present research contributes to the study of urban sprawl in Latin American cities, specifically in mid-sized metropolitan areas with intense expansion. The methodology allows a thorough examination of the empirical 


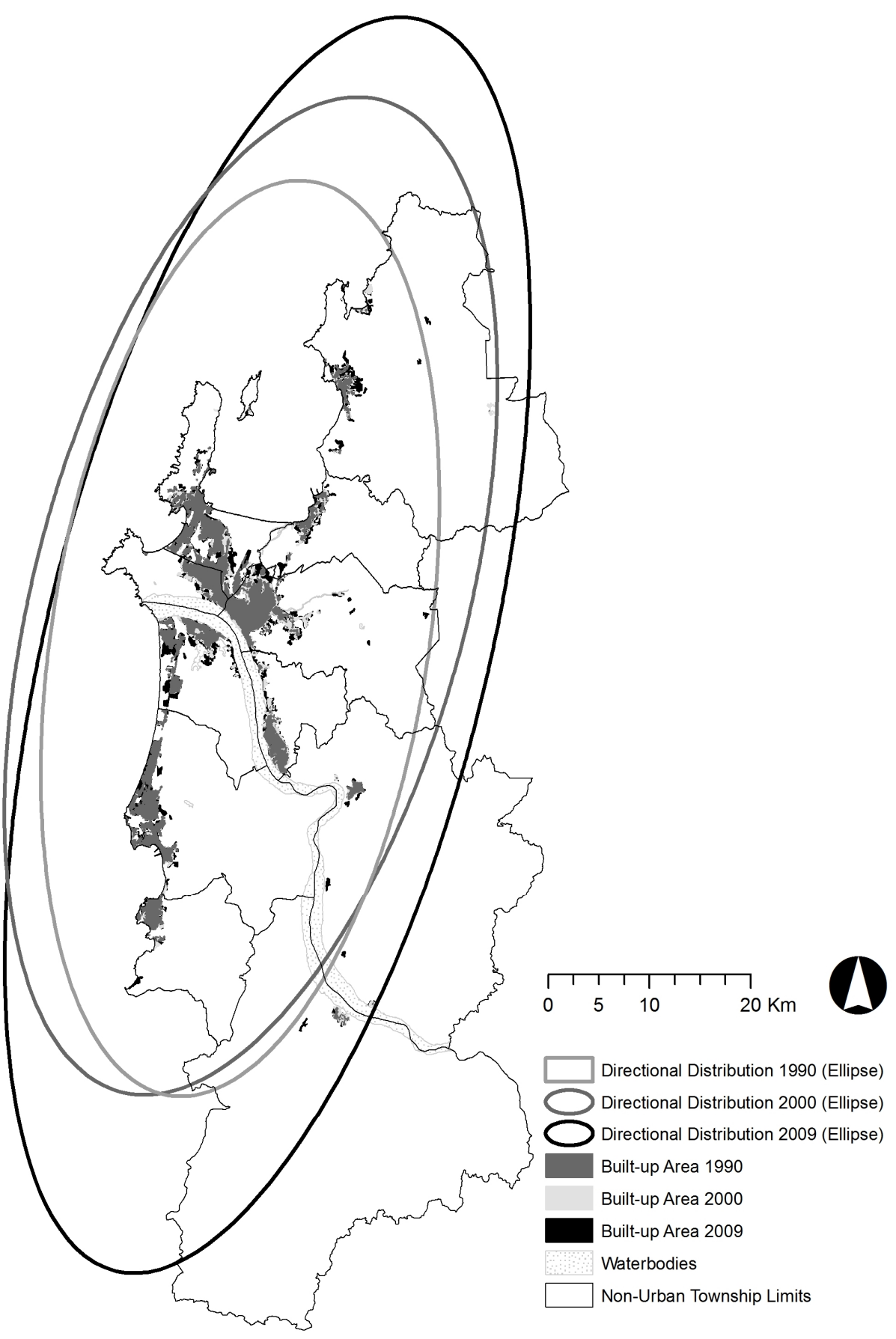

Figure 5. Standard deviational ellipses map.

evidence of urban land use, its compactness and complexity, and the spatial distance between new urbanized surfaces to central area.

Thus, the theoretical context linked to the influence of the neoliberal system and global economic tendencies in the process of urbanization can be related to the spatial dynamic of the CMA over the last 20 years. This process is not new, because it manifested in other medium size cities of the Biobío region such as Los Ángeles, redefin- ing the urban expansion in more polarized and fragmented spaces [40].

Our results about CMA indicate that the trend for horizontal and peripheral growth has been maintained since the 1990s, coinciding with a strengthening of the neoliberal model in Chile. This horizontal trend, associated with peripheral urbanization and influenced by the land market, has favored disperse, agglomerated, and complex urban expansion. In the case of CMA, the 
increase in the distances among new peripheral urban areas and the center can be evidences as an element of urban sprawl.

The case of CMA the urban sprawl related with the number of forms is not based on a fragmentation model that is not evident and is not highly influenced by the role of metropolitan centers. In this case, the hypothesis of urban sprawl indicates that areas of greater built-up will be accompanied by greater complexity but declining compactness, especially in the most urbanized and largest areas such as the central conurbations.

Although we do not note an intense fragmentation process, we do see progressive growth in the distance between the new forms, increasing the size of the ellipse by more than $1000 \mathrm{Km}^{2}$. The use of confidence ellipses is generally inconvenient given their high dependence on the points farthest from the downtown as this, in general, generates very large areas. However, this "disadvantage" is a boon to the present analysis as it is directly related to the phenomenon to be measured: the sprawl of urbanized forms.

Based on our results, we can conclude that the CMA is evolving into a mixed urban model, with first elements of sprawl occurring mainly on the periphery and near the largest population centers or in the polygon on the central area (conurbation) that concentrates infrastructure facilities and public services. The phase of spatial evolution of the CMA can be categorized as "agglomerated dispersion". In other words, cities that keep their size compact, but being dispersed in the periphery, making their forms more complex and increasing the distance among urbanized areas.

In CMA this process is closely tied to the social and political changes that occurred in Chile in the 1990s. However, these spatial tendencies towards more dispersed forms are far below of the means of cities from developed and developing countries. Latin American capitals are therefore within an international comparison. CMA is presented as a compact city without further complexities, in a context where most Latin American cities can be distinguished by their moderate centrality, density, complexity, centrality and a moderately low level of open space [20].

Eventhough authors consider the proposal by Huang et al. (2007) valuable, but a proposal that simplifies the complexity of Latin American cities; North American and European cities are not comparable with Latin American cities with the same indices or metrics, because Latin American cities take on more complex and concentrated recent forms. Agglomerated dispersion is the outcome of urban development consisting of a continuous, horizontal, extensive, and not evidently fragmented builtup area that loses compactness and gains complexity. The urban form tends to join and regroup in a dispersed oil stain. Compact areas are small, and they are located near the sea and in rural areas; urban growth is connected through fewer polygons or urban forms. Furthermore, the less compact, more complex forms are located in larger urban areas such as the central conurbation.

The specific spatial growth patterns for the built-up area of the CMA continued growing in the main center. The new sprawl consolidates the idea of a central urban conglomerate expanding along the banks of the Biobío River and presenting concentric or radial growth that is dispersed in the new built-up areas around the main centers in the periphery of the cities (Hualpén, Penco, Hualqui, and Santa Juana). Concepción and Talcahuano, the main centers, show tentacular growth along the highways.

The measures also suggest some ideas about the sustainability of the compact structures found in the urban centers versus scattered suburban growth in the periphery. Scattered urbanizations are located in the periphery, that is, in the areas between Concepción and Talcahuano and in the residential area of San Pedro. One main effect of this is that of being located in spaces exposed to natural risks (landslides and flooding). The disperse growth has been intense and temporally very fast, in complete contradiction with the geographic limitations that determine the territory in zones that are little apt environmentally for human settlements.

The CMA, with its complex built-up area, faces constant urban pressure whose dispersive trend is not the most appropriate given the goal of sustainable urban development, especially when considering the environmental and geographic factors that constrain horizontal expansion: the coastline, rivers, small lakes, and surrounding hills. For this reason, many new urban areas are developing in unsuitable directions, generally increasing exposure to natural risks [41]. Consequently, the recent urban sprawl observed in the CMA does not reflect a pattern of smart growth.

As can be seen, this is a functionally very dynamic and changing area, belonging to a metropolitan space, attractive for residential and renewal purposes. Thus, further studies are required to monitor the changes and to elucidate the factors that explain them. Another important idea is the process of polycentrism that runs parallel to sprawl and should be distinguished from this since these are two alternative processes. On the one hand, the area has grown in a disperse manner towards the peripheries and, on the other, the townships have retained average densities around their main downtown areas. In general, the densities of the periphery have not increased. Future research lines should aim to update the monitoring of urban sprawl and its relationship with polycentrism. It would be appropriate to detect whether the new peripheral growth has given rise to or seen the emergence of 
density-attracting downtowns.

Finally, the measures that help understanding the first degree or evidences of urban sprawl (GIS techniques, landscape metrics, and statistical analysis) have demonstrated their application and effectiveness in the modeling of dynamic phenomena in a mid-sized metropolitan area of Chile.

\section{Acknowledgements}

This research was sponsored by the projects FONDECYT No. 11090163: "Valoración del Territorio Metropolitano. Aproximaciones desde su Sostenibilidad y Evaluación Ambiental Estratégica" (Evaluation of the metropolitan territory by means of sustainable approaches and strategic environmental assessment). CONICYT/ FONDAP/15110020.

\section{REFERENCES}

[1] J. K. Brueckner, "Urban Sprawl: Lessons from Urban Economics," Brookings-Wharton Papers on Urban Affairs, 2001, pp. 65-97. doi:10.1353/urb.2001.0003

[2] P. W. G. Newman and J. R. Kenworthy, "Cities and Automobile Dependence: A Sourcebook," Gower Technical, Aldershot, 1989.

[3] I. Muñiz and A. Galindo, "Urban Form and the Ecological Footprint of Commuting. The Case of Barcelona," Ecological Economics, Vol. 55, No. 4, 2005, pp. 499-514. doi:10.1016/j.ecolecon.2004.12.008

[4] M. Munro, "Homo-Economicus in the City: Towards an Urban Socio-Economic Research Agenda," Urban Studies, Vol. 32, No. 10, 1995, pp. 1609-1621. doi: $10.1080 / 00420989550012267$

[5] P. Wilson, "Building Social Capital: A Learning Agenda for the Twenty-First Century," Urban Studies, Vol. 34, No. 5-6, 1997, pp. 745-760. doi:10.1080/0042098975808

[6] M. C. Derloo and S. Musterd, "Ethnic Clusters in Amsterdam, 1994-1996: A Micro-area Analysis," Urban Studies, Vol. 35, No. 3, 1998, pp. 385-396.

[7] I. Thomas, P. Frankhauser and C. Biernacki, "The Morphology of Built-Up Landscapes in Wallonia (Belgium): A Classication Using Fractal Indices," Landscape and Urban Planning, Vol. 84, No. 2, 2008, pp. 99-115. doi:10.1016/j.landurbplan.2007.07.002

[8] G. Galster, R. Hanson, M. Ratcliffe, M. Wolman, S. Coleman and J. Freihage, "Wrestling Sprawl to the Ground: Defining and Measuring an Elusive Concept," Housing Policy Debate, Vol. 12, No. 4, 2001, pp. 681717. doi:10.1080/10511482.2001.9521426

[9] M. Batty, "The Size, Scale, and Shape of Cities," Science, Vol. 319, No. 5864, 2008, pp. 769-771. doi:10.1126/science. 1151419

[10] J. Barredo and L. Demicheli, "Urban Sustainability in Developing Countries Megacities: Modelling and Predicting Future Urban Growth in Lagos," Cities, Vol. 20, No. 5, 2003, pp. 297-310.

\section{doi:10.1016/S0264-2751(03)00047-7}

[11] N. B. Grimm, S. H. Faeth, N. E. Golubiewski, C. L. Redman, J. Wu, X. Bai, et al., "Global Change and the Ecology of Cities," Science, Vol. 319, No. 5864, 2008, pp. 756-760. doi:10.1126/science.1150195

[12] United Nations, "World Urbanization Prospects," Department of Economic and Social Affairs, 2007. http://esa.un.org/unpd/wup/index.htm.

[13] C. de Mattos, "Santiago de Chile, Globalization and Metropolitan Expansion: What Was There Still Is," Latin American Regional Urban Studies Review, Vol. 25, No. 76, 1999, pp. 29-56.

doi:10.4067/S0250-71611999007600002

[14] J. X. Barros, "Urban Growth in Latin American Cities Exploring Urban Dynamics through Agent-Based Simulation," Ph.D. Thesis, University of London, London, 2004.

[15] R. Hidalgo and F. Arenas, "From Urban Country to Metropolitan. Recent Transformation in the Chilean Cities," In: R. Hidalgo, C. De Mattos and F. Arenas, Eds., From Urban country to Metropolitan, GEOlibro, Pontifical Catholic University of Chile, Santiago, 2009, pp. 9-29.

[16] P. Ciccolella, "Recent Transformation in the Latin American Metropolis," In: F. M. Victoria and R. Gurevich, Eds., Geography: New Topics, New Questions. An Agenda for Teaching, Buenos Aires, Biblos, 2007, pp. 17-38.

[17] P. Mieszkowski and E. Mills, "The Causes of Metropolitan Suburbanization," Journal of Economic Perspectives, Vol. 7, No. 3, 1993, pp. 135-147. doi:10.1257/jep.7.3.135

[18] A. G. Champion, "Population Change and Migration in Britain Since 1981: Evidence for Continuing Deconcentration," Environment and Planning A, Vol. 26, No. 10, 1994, pp. 1501-1520.

[19] P. C. Cheshire and D. G. Hay, "Urban Problems in Western Europe: An Economic Analysis," Unwin Hyman, London, 1989.

[20] J. Huang, X. Lu and J. M. Sellers, “A Global Comparative Analysis of Urban Form: Applying Spatial Metrics and Remote Sensing," Landscape and Urban Planning, Vol. 82, No. 4, 2007, pp. 184-197. doi:10.1016/j.landurbplan.2007.02.010

[21] C. de Mattos, "Transformación de las Ciudadess Latinoamericanas Impactos de la Globalización?" Estudios latinoamericanos Urbanos Regionales (EURE), Vol. 28, No. 85,2002 , pp. 5-10. doi:10.4067/S0250-71612002008500001

[22] M. K. Jat, P. K. Garg and D. Khare, "Monitoring and Modeling of Urban Sprawl Using Remote Sensing and GIS Techniques," International Journal of Applied Earth Observation and Geoinformation, Vol. 10, No. 1, 2008, pp. 26-43. doi:10.1016/j.jag.2007.04.002

[23] W. Ji, M. Jia, R. Wahad and K. Underhill, "Characterizing Urban Sprawl Using Multi-Stage Remote Sensing Images and Landscape Metrics," Computers. Environment and Urban Systems, Vol. 30, No. 6, 2006, pp. 861879. doi:10.1016/i.compenvurbsys.2005.09.002

[24] H. S. Chae, S. J. Kim and J. A. Ryu, "A Classification of 
Multitemporal Landsat TM Data Using Principal Component Analysis and Artificial Neural Network," Geosciences and Remote Sensing, Vol. 1, No. 1, 1997, pp. 517-520.

[25] X. Li and A. Yeh, "Principal Component Analysis of Stacked Multi-Temporal Images for the Monitoring of Rapid Urban Expansion in the Pearl River Delta," International Journal Remote Sensing, Vol. 19, No. 8, 1998, pp. 1501-1518. doi:10.1080/014311698215315

[26] E. Irwin and N. Bockstael, "The Evolution of Urban Sprawl: Evidence of Spatial Heterogeneity and Increasing Land Fragmentation," PNAS, Vol. 104, No. 52, 2007, pp. 20672-20677. doi:10.1073/pnas.0705527105

[27] G. Shen, "Fractal Dimension and Fractal Growth of Urbanized Areas," International Journal of Geographical Science, Vol. 16, No. 5, 2002, pp. 419-437. doi:10.1080/13658810210137013

[28] M. Zhu, N. Jiang, J. Li, J. Xu and Y. Fan, "The Effects of Sensor Spatial Resolution and Changing Grain Size on Fragmentation Indices in Urban Landscape," International Journal of Remote Sensin,g Vol. 27, No. 21, 2006, pp. 4791-4805. doi:10.1080/01431160600702442

[29] S. Mubareka, E. Koomen, C. Estreguil and C. Lavalle, "Development of a Composite Index of Urban Compactness for Land Use Modelling Applications," Landscape and Urban Planning, Vol. 103, No. 3-4, 2011, pp. 303317. doi:10.1016/j.landurbplan.2011.08.012

[30] M. Mardones and V. Vidal, "Zonning and Assesment of Natural Geomorphological Risk. A Instrument of Urban Planning in the City of Concepción," Latin American Urban Planning Review, Vol. 27, No. 81, 2004, pp. 97122.

[31] SEREMI-MINVU (Secretaría Regional Ministerial de Vivienda y Urbanismo Región del Bío-Bío), Report of Urban Metropolitan Planning of Concepción, Concepción, 2003.

[32] C. Rojas, I. Muñiz and M. A. García-López, "Estructura urbana y Policentrismo en el Área Metropolitana de Concepción," Latin American Regional Urban Studies, Vol. 35, No. 105, 2009, pp. 47-70.

[33] C. Rojas, S. Opazo and E. Jaque, "Growth Dynamics and Patterns in the Concepción Metropolitan Area. Last Decades Trends," In: R. Hidalgo, C. De Mattos and F. Arenas, Eds., From Urban Country to the Metropolitan Country, GEOlibros-Instituto de Geografía Pontificia Universidad Católica de Santiago, 2011, pp. 257-268.
[34] L. Pérez and E. Salinas, "Urban Growth and Globalization: Transformations of the Metropolitan Area of Concepción, Chile, 1992-2002, Scripta Nov," Geography and Social Science Electronic Review, Vol. XI, No. 51, 2007. http://www.ub.edu/geocrit/sn/sn-251.htm

[35] C. Rojas and W. Plata, "Metropolitan Area of Concepción: Driving Factors of Urban Growth (2001-2009) by a Spatial Logistic Regression Model," International Congress of Territorial Planning and Geographical Information Technology, Tegucigalpa, Honduras, 2010.

[36] F. Machiavello and R. Hidalgo, "Socio-Spatial Consequenses of the Social Housing in the Metropolitan Area of Concepción: Integrated Neighborhoods or Urban Spaces?" In: L. Pérez and R. Hidalgo, Eds., Metropolitan Area of Concepción (MAC), Evolution and Challenges, Geolibros, Institute of Geography Pontifical Catholic, University of Chile, Santiago, 2010, pp. 153-170.

[37] A. Pauchard, M. Aguayo, E. Peña and R. Urrutia, "Multiple Effects of Urbanization on the Biodiversity of Developing Countries: The Case of a Fast-Growing Metropolitan Area (Concepción, Chile)," Biological Conservation, Vol. 127, No. 3, 2006, pp. 272-281. doi:10.1016/j.biocon.2005.05.015

[38] L. Perez and P. Fuentes, "The Intercommunal Urban Plan of Concepción in 1963. Beginning of the Metropolitan Planning," In: L. Pérez and R. Hidalgo, Eds., Metropolitan Area of Concepción (MAC), Evolution and Challenges, Geolibros, Institute of Geography Pontifical Catholic, University of Chile, Santiago, 2011, pp. 45-58.

[39] I. Gysling and A. Hoffmann. "Intercommunal and Communal Planning of the Metropolitan Area of Concepción," In: L. Pérez and R. Hidalgo, Eds., Metropolitan Area of Concepción (MAC), Evolution and Challenges, Geolibros, Institute of Geography Pontifical Catholic, University of Chile, Santiago, 2010, pp. 59-82.

[40] G. Azócar, H. Romero, R. Sanhueza, C. Vega, M. Aguayo and M. Muñoz, "Urbanization Patterns and Their Impacts on Social Restructuring of Urban Space in Chilean Mid-Cities: The Case of Los Angeles, Central Chile," Land Use Policy, Vol. 24, No. 1, 2007, pp. 199-211. doi:10.1016/j.landusepol.2005.04.003

[41] C. Rojas, J. Pino and E. Jaque, "Strategic Environmental Assessment in Latin America: A Methodological Proposal for Urban Planning in the Metropolitan Area of Concepción (Chile)," Land Use Policy, Vol. 30, No. 1, pp. 519-527. doi:10.1016/j.landusepol.2012.04.018 